\title{
TMD and chronic pain: A current view
}

\author{
Bruno D’Aurea Furquim¹ㄴ. Lívia Maria Sales Pinto Flamengui², Paulo César Rodrigues Conti³
}

DOI: $h$ ttp://dx.doi.org/10.1590/2176-9451.20.1.127-133.sar

This review aims at presenting a current view on the physiopathologic mechanisms associated with temporomandibular disorders (TMDs). While joint pain is characterized by a well-defined inflammatory process mediated by tumor necrosis factor- $\alpha$ and interleukin, chronic muscle pain presents with enigmatic physiopathologic mechanisms, being considered a functional pain syndrome similar to fibromyalgia, irritable bowel syndrome, interstitial cystitis and chronic fatigue syndrome. Central sensitization is the common factor unifying these conditions, and may be influenced by the autonomic nervous system and genetic polymorphisms. Thus, TMDs symptoms should be understood as a complex response which might get worse or improve depending on an individual's adaptation.

Keywords: Temporomandibular disorder. Myofascial painful syndrome. Central nervous system sensitization. Autonomic nervous system.

Esta revisão teve como objetivo apresentar uma visão atualizada dos mecanismos fisiopatológicos relacionados às disfunções temporomandibulares (DTMs). Enquanto a dor articular é caracterizada por um processo inflamatório bem descrito - mediado pelo fator de necrose tumoral alfa (TNF- $\alpha$ ) e interleucinas -, a dor muscular crônica apresenta mecanismos fisiopatológicos mais obscuros, sendo considerada uma síndrome dolorosa funcional, assim como a fibromialgia, a síndrome do intestino irritável, a cistite intersticial e a síndrome da fadiga crônica. A sensibilização central é o processo comum, unificador, dessas condições, podendo sofrer influência do sistema nervoso autonômico e de polimorfismos genéticos. Portanto, os sintomas das DTMs devem ser entendidos como uma resposta complexa, podendo ser amplificados ou atenuados em função da adaptação individual.

Palavras-chave: Disfunções temporomandibulares. Síndrome dolorosa miofascial. Sensibilização do sistema nervoso central. Sistema nervoso autônomo.

" The authors report no commercial, proprietary or financial interest in the products or companies described in this article.
How to cite this article: Furquim BD, Flamengui LMSP, Conti PCR. TMD and chronic pain: A current view. Dental Press J Orthod. 2015 JanFeb;20(1):127-33. DOI: http://dx.doi.org/10.1590/2176-9451.20.1.127-133.sar

Submitted: November 03, 2014

Revised and accepted: December 02, 2014

Contact address: Bruno D'Aurea Furquim

Al. Octávio Pinheiro Brisola, 9-75 - CEP 17012-901 - Bauru - SP - Brazil E-mail: brunofurquim@hotmail.com
${ }^{2} \mathrm{PhD}$ in Oral Rehabilitation, School of Dentistry - USP/Bauru.

${ }^{3}$ Full professor, Department of Prosthesis, School of Dentistry — USP/Bauru. 


\section{INTRODUCTION}

Temporomandibular disorders (TMDs) represent a set of muscle-skeletal disorders associated with the masticatory system and a number of symptoms. Pain is the most common symptom usually concentrated in masticatory muscles and/or temporomandibular joints (TMJs), but exacerbated by mandibular movement and stomatognathic functions. ${ }^{1}$ TMD seems to be of multifactorial etiology, including parafunctional habits, bruxism, deleterious body posture, occlusal features, growth abnormalities, trauma, overload and stress. ${ }^{2-8}$

Despite extensive literature on the topic, there is a need for further prospective, controlled, randomized, long-term clinical trials in order to establish a concrete cause and effect relationship. On the other hand, significant advance has been made with regard to the physiopathologic mechanisms associated with this condition.

\section{JOINT PAIN AND}

\section{INFLAMMATORY CYTOKINES}

The pathophysiology of TMJ pain is better understood than masticatory muscle pain; thus, the former is a convenient starting point to discuss TMDs pain mechanisms. ${ }^{9}$ Disc displacement and degenerative joint pain are commonly associated with TMJ. Osteoarthritis is characterized by articular cartilage deterioration and abrasion, as well as by remodeling thickening of subjacent bone. It causes secondary inflammatory reactions, such as joint effusion, revealed by magnetic resonance. The TMJ might also be affected by rheumatoid arthritis, an autoimmune condition that results in inflammatory joint destruction. Chemical mediators and cytokines play an important role in both rheumatoid arthritis and osteoarthritis. Regardless of the pathological condition, degenerated TMJ might lead to a number of morphological defects associated with pain and significant loss of articular function. ${ }^{9-13}$

TMJ inflammation results in the release of various proinflammatory cytokines, particularly tumor necrosis factor- $\alpha$ (TNF- $\alpha)$ and interleukins, ${ }^{14,15,16}$ which contribute to articular cartilage remodeling and deterioration. ${ }^{17}$ Interleukin-1 (IL-1) and interleukin-6 (IL-6) have been found in cases of osteoarthritis and temporomandibular joints with internal disarrangements. ${ }^{18,19,20}$
Cytokines are mainly produced by macrophages penetrating into the synovium. Synovium inflammation affects the viscosity of synovial fluid and leads to insufficient lubrication and nourishment of cartilage and disc. ${ }^{21}$

Inflammatory mediators stimulate the nociceptors of TMJ and increase the release of CGRP (calcitonin gene related peptide) and substance $\mathrm{P}$, which result in swelling, redness and a rise in temperature. This process is known as neurogenic inflammation. ${ }^{22}$ Increased nociceptive stimuli in inflamed joints also contribute to inducing central sensitization and reflex of mandibular muscles (protective contraction). ${ }^{15,23}$

\section{TMD: A FUNCTIONAL PAIN SYNDROME}

Chronic TMD, especially myofascial TMD, is considered a functional pain syndrome similar to fibromyalgia, irritable bowel syndrome, interstitial cystitis and chronic fatigue syndrome. These conditions appear to have common etiological factors which explain the great comorbidity of symptoms. It is interesting to notice that functional disorders tend not only to cumulatively affect an individual, but also to present central sensitization and amplified pain perception. Such disorders have similar treatment response, and may be treated with antidepressant drugs and cognitive behavioral therapy. The pathophysiologic mechanisms of such pain conditions remain unknown. However, it is believed that amplified pain perception, alterations in brain activity as well as in immune and neuroendocrine activities, and genetic predisposition may be involved. Further studies should be capable of revealing a predominant or unifying mechanism that explains such functional alterations..$^{24,25,26}$

In cases of functional pain syndrome, pain is no longer a protection factor. Pain is spontaneously felt and might be triggered by innocuous stimuli (allodynia); it might be excessive and prolonged and occurring in response to nociceptive stimuli (hyperalgesia); and it might spread beyond the injured site (secondary hyperalgesia). ${ }^{27}$ Should hyperalgesia occur after tissue is injured, it results from increased sensitivity of primary afferent nociceptors found around the injured site (peripheral sensitization) ${ }^{28}$ and increased excitability of secondary afferent nociceptors found in the spinal cord (central sensitization). ${ }^{29}$ 


\section{PAIN CHRONICITY}

The phenomenon of peripheral sensitization occurs as a result of inflammatory response provoked by a tissue injury. Should that be the case, allodynia and hyperalgesia occur due to inflammatory mediators released at the site of lesion. For instance, whenever a tooth is extracted, the site of inflammation presents with increased sensitivity to pressure (hyperalgesia) mediated by sensitized nociceptors. Nevertheless, such reaction is expected to restore within a reasonable period of time due to decreased nociceptors activity and consequent decreased afferent activity of the dorsal horn. However, the inflammatory process and its consequent afferent activity might be intense enough so as to establish a central process. ${ }^{30}$

C-fibers are the first nociceptors involved in central sensitization onset, as they produce slow synaptic currents and repetitive stimuli, thereby increasing depolarization in the spinal cord dorsal horn as a result of activating the calcium channels that depend on binders. Initially, calcium channels are opened, quickly and for a short period of time, by AMPA ( $\alpha$-Amino-3-hydroxy-5-methyl-4isoxazolepropionic acid) receptors. This process allows calcium ions to penetrate the cell and favors depolarization of wide dynamic range neurons which can respond to a large variety of stimuli. In addition to activating ionotropic receptors, glutamate and substance $\mathrm{P}$ also activate metabotropic receptors, thereby releasing more calcium to intracell vesicles, increasing the concentration of calcium ion and, as a result, activating protein-kinase enzymes that phosphorylate the N-methyl-D-aspartate (NMDA) receptor. In normal conditions, the channel bound to the NMDA receptor is blocked by magnesium ions. Once this receptor is activated, it is phosphorylated and magnesium ions are released, thereby opening the channel and allowing calcium ions to enter the cell. Unlike what happens with the AMPA receptor, activation of the NMDA receptor is enduring and hardly ever reverted..$^{30,31,32}$

Although activation of NMDA receptors seem to play a major role in central sensitization, a single molecular mechanism responsible for the process has not yet been identified, as it might be mediated by different processes capable of producing a variety of alterations in the somatosensory system. Of the many alterations, the following apply: increased excitability of neuronal membrane, facilitation of synapses and decreased inhibitory influence of dorsal horn neurons. Thus, central sensitization might lead to pain despite absence of pathologies or peripheral pain stimuli and, therefore, it should target the central nervous system, not the peripheral one. ${ }^{27,33}$

\section{EMOTIONS AND THE AUTONOMIC NERVOUS SYSTEM}

Lorduy et $\mathrm{al}^{24}$ found that central sensitization symptoms are associated with stronger emotional suffering in TMD patients. Other studies reveal that psychological factors vary among TMD patients and control groups..$^{34,35,36}$ Additionally, TMD patients suffering from depression and anxiety have an increased risk of feeling joint and muscle pain, respectively. ${ }^{37}$

The relationship established between anxiety or stress and TMD is simply explained by the greater contraction of masticatory muscles happening as a result of TMD, since muscle hyperactivity is one of the most frequent mechanisms influencing myofascial pain. ${ }^{38,39}$ An experiment in which patients were subject to stressful conditions revealed that myofascial TMD patients presented with increased electromyographic activity of masseter and frontal muscles in comparison to the control. ${ }^{40,41}$ Nevertheless, there is a more complex explanation for such relationship.

Mild negative emotions might favor the occurrence of pain. In this context, whenever damage is unpredictable, pain plays an important role in detecting risky situations so as to preserve tissue integrity. It is an adaptive means of promoting environmental monitoring, a sensory monitoring mechanism to increase threat detection. ${ }^{42,43,44} \mathrm{Hav}-$ ing the expectation to feel pain may increase pain sensitivity, particularly when the moment of pain cannot be anticipated. ${ }^{44}$

In situations involving intense negative emotions, whenever thread is imminent and predictable, fighting and escapement reactions establish hypoalgesia as a defense mechanism. An interesting experiment revealed that Vietnam veterans with post-traumatic stress disorder (PTSD) reported 30\% less pain when stimulated by heat after being exposed to battle videos. There was no reduction in pain intensity when veterans were subject to naloxone, an opioid 
receptor antagonist. Results clearly revealed analgesia induction mediated by opioid and induced by stress in PTSD patients. ${ }^{45}$

The amygdala detects danger by causing fear and anxiety and, as a result, putting us in state of alert. The connections between amygdala and periaqueductal gray are involved in the modulation of emotion-mediated nociception. An unregulated hazard detection circuit in functional pain syndrome patients might decrease the threshold of negative, intense, long-term emotional experiences. Thus, unlike healthy patients, intense negative emotions might lead to hyperalgesia, not hypoalgesia. ${ }^{46,47}$

Diffuse noxious inhibitory controls (DNIC) are the main endogenous pain inhibitory systems. The literature asserts that a nociceptive stimulus suppresses another nociceptive stimulus ("pain inhibits pain" mechanism) provided that body surfaces under stimulation are at a certain distance. Patients with fibromyalgia subjected to cold pressor tests are less likely to respond to DNIC, thereby making endogenous pain inhibitory system deficiency explicit. ${ }^{48,49}$

Robinson et $a l^{50}$ proved that anxiety is positively associated with the process of temporal somatization, thereby suggesting that anxiety might contribute to central pain processing. The same effect has been repeated by Granot et al..$^{51}$ Likewise, Edwards et al ${ }^{52}$ suggested that pain catastrophizing might produce the same effect. Not coincidentally, a number of studies highlight the correlation between negative emotions and painful functional disorders. ${ }^{53}$

Psychological stress is known for inducing adaptive responses of physiological systems, including increased hypothalamo-hypophyseal adrenal system activity. These responses induce cortisol secretion by the adrenal cortex and increase sympathetic adrenal medullary system (SAM) activity which, in turn, isolates adrenalin and noradrenaline through peripheral sympathetic nerve endings and adrenal medulla. ${ }^{54-57}$ Trait-anxiety (State-Trait Anxiety Inventory - STAI) and altered plasmatic cortisol concentrations, adrenalin and noradrenaline were significantly associated after psychologically-induced stress (mental arithmetic test) in myofascial TMD patients; however, healthy individuals did not behave accordingly. Results suggest that anxiety levels, particularly trait-anxiety, might be associated with greater sensitivity in hypothalamo-hypophyseal adrenal system and sympathetic adrenal medullary system in patients under myofascial pain. ${ }^{35}$

Emerging evidence suggests that unregulated autonomic nervous system contributes to TMD development and chronicity. ${ }^{58-62}$ When compared to healthy individuals, TMD patients present with autonomic activity dysfunction characterized by decreased heart rate variability at rest as well as in response to physical (standing position) and psychological (Stroop test) stressors, thereby proving that cardiac parasympathetic tone remained low at all times and frequency in comparison to control. TMD patients also present reduced baroreceptor sensitivity. ${ }^{63}$ Other studies also suggest greater sympathetic tone as a result of unregulated central in TMD and other chronic muscle diseases patients. ${ }^{61,64}$

Chalaye et $\mathrm{a}^{65}$ confirm the presence of increasing somatic hyperalgesia levels in irritable bowel syndrome and fibromyalgia patients. Likewise, the authors also found a dysfunctional pattern for pain inhibition followed by abnormal autonomic responses, which kept patients (especially fibromyalgia ones) in a state of sympathetic hyperactivity. ${ }^{65}$ Recent results reveal reduced baroreceptor sensitivity in fibromyalgia patients. ${ }^{66,67,68}$ Baroreceptor activity has also been associated with descending pain inhibitory system efficiency. ${ }^{69,70,71}$ Therefore, abnormal baroreceptor activity not only explains why fibromyalgia patients present with deficient descending pain inhibition along with poor anatomical adjustments, ${ }^{72}$ but also why they often suffer from comorbidities such as fatigue, orthostatic intolerance, sleep disorders and impaired cognition. ${ }^{66,73}$

Unregulated central in TMD patients causes the autonomic nervous system to react less to physical or psychological stress, since the sympathetic tone is high even at rest. This characteristic has been associated with COMT gene variables (SNPs or single-nucleotide polymorphisms) ${ }^{74}$ responsible for provoking 
an hyperadrenergic state. COMT variables are also associated with hypervigilance, anxiety, pain hypersensitivity and inefficient opioid system. ${ }^{75,76,77}$ Thus, COMT gene polymorphism illustrates how genetics embraces a vast universe of investigation and research.

The different physiopathologic mechanisms involved in the multifactorial nature of TMDs suggest that distinct genetic loci are connected in such a way that each locus produces minor effects and interacts with environmental exposure. ${ }^{78,79}$

REFERENCES

1. Leeuw R. Dor orofacial: guia de avaliação, diagnóstico e tratamento. São Paulo: Quintessence; 2010

2. Harkins SJ. Extrinsic trauma and temporomandibular dysfunction. Cranio: J Craniomandibular Pract. 1986:4(1):1-2

3. Nilner M. Relationships between oral parafunctions and functional disturbances in the stomatognathic system among 15- to 18-year-olds. Acta Odontol Scand. 1983;41(4):197-201.

4. Schellhas KP, Pollei SR, Wilkes $\mathrm{CH}$. Pediatric internal derangements of the temporomandibular joint: effect on facial development. An J Orthod Dentofacial Orthop. 1993:104(1):51-9.

5. Pullinger AG, Seligman DA, Gornbein JA. A multiple logistic regression analysis of the risk and relative odds of temporomandibular disorders as a function of common occlusal features. J Dent Res. 1993;72(6):968-79.

\section{CONCLUSION}

TMD symptoms should be understood as a complex individual response with unique complaints and which might get worse or improve depending on an individual's genetic composition.

Due to multiple etiological factors and different individual adaptation, multidisciplinary therapy should be encouraged. Likewise, future research elucidating neurobehavioral processes underlining chronic pain should also be encouraged.
6. Simons DG, Travell JG, Simons LS. Pain and Dysfunction: The Trigger Point Manual. 2nd ed. Baltimore: Lipincot Williams \& Wilkins; 1999.

7. Reissmann DR, John MT, Schierz O, Seedorf H, Doering S. Stress-related adaptive versus maladaptive coping and temporomandibular disorder pain. J Orofac Pain. 2012;26(3):181-90.

8. Buckingham RB, Braun T, Harinstein DA, Oral K, Bauman D, Bartynski $W$, et al. Temporomandibular joint dysfunction syndrome: a close association with systemic joint laxity (the hypermobile joint syndrome). Oral Surg Oral Med Oral Pathol. 1991;72(5):514-9.

9. Cairns BE. Pathophysiology of TMD pain--basic mechanisms and their implications for pharmacotherapy. J Oral Rehabil. 2010;37(6):391-410

10. Tanaka E, Detamore MS, Mercuri LG. Degenerative disorders of the temporomandibular joint: etiology, diagnosis, and treatment. J Dent Res. 
2008:87(4):296-307

11. Zarb GA, Carlsson GE. Temporomandibular disorders: osteoarthritis. J Orofac Pain. 1999;13(4):295-306

12. Israel HA, Ward JD, Horrell B, Scrivani SJ. Oral and maxillofacial surgery in patients with chronic orofacial pain. J Oral Maxillofac Surg. 2003:61(6):662-7.

13. Brinckerhoff $C E$. Joint destruction in arthritis: metalloproteinases in the spotlight. Arthritis Rheum. 1991;34(9):1073-5

14. de Leeuw R. Internal derangements of the temporomandibular joint. Oral Maxillofac Surg Clin North Am. 2008:20(2):159-68.

15. Sessle BJ. Peripheral and central mechanisms of orofacial pain and their clinical correlates. Minerva Anestesiol. 2005:71(4):117-36.

16. Wiese M, Svensson P, Bakke M, List T, Hintze H, Petersson A, et al. Association between temporomandibular joint symptoms, signs, and clinical diagnosis using the RDC/TMD and radiographic findings in temporomandibular joint tomograms. J Orofac Pain. 2008;22(3):239-51

17. Vernal R, Velasquez E, Gamonal J, Garcia-Sanz JA, Silva A, Sanz M. Expression of proinflammatory cytokines in osteoarthritis of the temporomandibular joint. Arch Oral Biol. 2008;53(10):910-5.

18. Holt I, Cooper RG, Denton J, Meager A, Hopkins SJ. Cytokine interrelationships and their association with disease activity in arthritis. Brit J Rheumatol. 1992;31(11):725-33.

19. Shafer DM, Assael L, White LB, Rossomando EF. Tumor necrosis factor-alpha as a biochemical marker of pain and outcome in temporomandibular joints with internal derangements. J Oral Maxillofac Surg. 1994:52(8):786-91; discussion 91-2

20. Fu K, Ma X, Zhang Z, Chen W. Tumor necrosis factor in synovial fluid of patients with temporomandibular disorders. J Oral Maxillofac Surg. 1995:53(4):424-6.

21. Smith AJ, Basu MK, Speculand B, Kassem MA, Lloyd JM. Synovial fluid glycosaminoglycan (acid mucopolysaccharide) analysis in assessment of temporomandibular joint dysfunction. A pilot study. Br J Oral Maxillofac Surg. 1989:27(5):853-61

22. Takeuchi Y, Zeredo JL, Fujiyama R, Amagasa T, Toda K. Effects of experimentally induced inflammation on temporomandibular joint nociceptors in rats. Neuroscience Lett. 2004;354(2):172-4.

23. Yu XM, Sessle BJ, Haas DA, Izzo A, Vernon H, Hu JW. Involvement of NMDA receptor mechanisms in jaw electromyographic activity and plasma extravasation induced by inflammatory irritant application to temporomandibular joint region of rats. Pain. 1996:68(1):169-78

24. Lorduy KM, Liegey-Dougall A, Haggard R, Sanders CN, Gatchel RJ. The prevalence of comorbid symptoms of central sensitization syndrome among three different groups of temporomandibular disorder patients. Pain Pract. 2013:13(8):604-13.

25. Suma S, Veerendra Kumar B. Temporomandibular disorders and functional somatic syndromes: deliberations for the dentist. Indian J Dent Res. 2012:23(4):529-36

26. Kim SE, Chang L. Overlap between functional Gl disorders and other functional syndromes: what are the underlying mechanisms? Neurogastroenterol Motil. 2012:24(10):895-913.

27. Latremoliere A, Woolf CJ. Central sensitization: a generator of pain hypersensitivity by central neural plasticity. J Pain. 2009:10(9):895-926

28. Raja SN, Campbell JN, Meyer RA. Evidence for different mechanisms of primary and secondary hyperalgesia following heat injury to the glabrous skin. Brain. 1984:107 (Pt 4):1179-88

29. Woolf CJ, Wall PD. Relative effectiveness of $C$ primary afferent fibers of different origins in evoking a prolonged facilitation of the flexor reflex in the rat. J Neurosci. 1986:6(5):1433-42

30. Merrill RL. Central mechanisms of orofacial pain. Dent Clin North Am 2007:51(1):45-59

31. Thompson SW, Woolf CJ, Sivilotti LG. Small-caliber afferent inputs produce a heterosynaptic facilitation of the synaptic responses evoked by primary afferent A-fibers in the neonatal rat spinal cord in vitro. J Neurophysiol. 1993;69(6):2116-28

32. Burstein R, Yamamura H, Malick A, Strassman AM. Chemical stimulation of the intracranial dura induces enhanced responses to facial stimulation in brain stem trigeminal neurons. J Neurophysiol. 1998;79(2):964-82.

33. Woolf CJ, Salter MW. Neuronal plasticity: increasing the gain in pain. Science. 2000;288(5472):1765-9

34. Harness DM, Donlon WC, Eversole LR. Comparison of clinical characteristics in myogenic, TMJ internal derangement and atypical facial pain patients. Clin J Pain. 1990;6(1):4-17.

35. Yoshihara T, Shigeta K, Hasegawa H, Ishitani N, Masumoto Y, Yamasaki Y. Neuroendocrine responses to psychological stress in patients with myofascial pain. J Orofac Pain. 2005:19(3):202-8

36. Butterworth JC, Deardorff WW. Psychometric profiles of craniomandibular pain patients: identifying specific subgroups. Cranio. 1987:5(3):225-32.

37. Kindler S, Samietz S, Houshmand M, Grabe HJ, Bernhardt O, Biffar R, et al. Depressive and anxiety symptoms as risk factors for temporomandibular joint pain: a prospective cohort study in the general population. J Pain. 2012;13(12):1188-97.

38. Yemm R. Neurophysiologic studies of temporomandibular joint dysfunction Oral Sci Rev. 1976:7:31-53.

39. Miller VJ, Yoeli Z, Barnea E, Zeltser C. The effect of parafunction on condyla asymmetry in patients with temporomandibular disorders. J Oral Rehabil. 1998;25(9):721-4

40. Kapel L, Glaros AG, McGlynn FD. Psychophysiological responses to stress in patients with myofascial pain-dysfunction syndrome. J Behav Med. 1989:12(4):397-406

41. Flor H, Birbaumer N, Schulte W, Roos R. Stress-related electromyographic responses in patients with chronic temporomandibular pain. Pain. 1991:46(2):145-52.

42. Meagher MW, Arnau RC, Rhudy JL. Pain and emotion: effects of affective picture modulation. Psychos Med. 2001;63(1):79-90

43. Rhudy JL, Meagher MW. Fear and anxiety: divergent effects on human pain thresholds. Pain. 2000;84(1):65-75.

44. Walters ET. Injury-related behavior and neuronal plasticity: an evolutionary perspective on sensitization, hyperalgesia, and analgesia. Int Rev Neurobiol. 1994:36:325-427

45. Pitman RK, van der Kolk BA, Orr SP, Greenberg MS. Naloxone-reversible analgesic response to combat-related stimuli in posttraumatic stress disorder. A pilot study. Arch Gen Psychiatry. 1990;47(6):541-4

46. Berman SM, Naliboff BD, Suyenobu B, Labus JS, Stains J, Ohning G, et al. Reduced brainstem inhibition during anticipated pelvic visceral pain correlates with enhanced brain response to the visceral stimulus in women with irritable bowel syndrome. J Neurosci. 2008;28(2):349-59. 
47. Arnold BS, Alpers GW, Suss H, Friedel E, Kosmutzky G, Geier A, et al. Affective pain modulation in fibromyalgia, somatoform pain disorder, back pain, and healthy controls. Eur J Pain. 2008;12(3):329-38.

48. Julien N, Goffaux P, Arsenault P, Marchand S. Widespread pain in fibromyalgia is related to a deficit of endogenous pain inhibition. Pain. 2005;114(1-2):295-302.

49. Normand E, Potvin S, Gaumond I, Cloutier G, Corbin JF, Marchand S Pain inhibition is deficient in chronic widespread pain but normal in major depressive disorder. J Clin Psychiatry. 2011;72(2):219-24.

50. Robinson ME, Wise EA, Gagnon C, Fillingim RB, Price DD. Influences of gender role and anxiety on sex differences in temporal summation of pain. J Pain. 2004;5(2):77-82

51. Granot M, Granovsky Y, Sprecher E, Nir RR, Yarnitsky D. Contact heatevoked temporal summation: tonic versus repetitive-phasic stimulation. Pain. 2006:122(3):295-305

52. Edwards RR, Smith MT, Kudel I, Haythornthwaite J. Pain-related catastrophizing as a risk factor for suicidal ideation in chronic pain. Pain. 2006:126(1-3):272-9.

53. Henningsen P, Zimmermann T, Sattel H. Medically unexplained physical symptoms, anxiety, and depression: a meta-analytic review. Psychosom Med. 2003:65(4):528-33.

54. Axelrod J, Reisine TD. Stress hormones: their interaction and regulation. Science. 1984:224(4648):452-9

55. Uchino BN, Cacioppo JT, Malarkey W, Glaser R. Individual differences in cardiac sympathetic control predict endocrine and immune responses to acute psychological stress. J Pers Soc Psychol. 1995:69(4):736-43.

56. Schommer NC, Hellhammer DH, Kirschbaum C. Dissociation between reactivity of the hypothalamus-pituitary-adrenal axis and the sympatheticadrenal-medullary system to repeated psychosocial stress. Psychosom Med. 2003;65(3):450-60.

57. McEwen BS. Protective and damaging effects of stress mediators. New Eng J Med. 1998:338(3):171-9

58. Bragdon EE, Light KC, Costello NL, Sigurdsson A, Bunting S, Bhalang K, et al. Group differences in pain modulation: pain-free women compared to pain-free men and to women with TMD. Pain. 2002;96(3):227-37.

59. Carlson CR, Okeson JP, Falace DA, Nitz AJ, Curran SL, Anderson D. Comparison of psychologic and physiologic functioning between patients with masticatory muscle pain and matched controls. J Orofac Pain. 1993:7(1):15-22

60. de Abreu TC, Nilner M, Thulin T, Vallon D. Office and ambulatory blood pressure in patients with craniomandibular disorders. Acta Odontol Scand. 1993:51(3):161-70.

61. Light KC, Bragdon EE, Grewen KM, Brownley KA, Girdler SS, Maixner W. Adrenergic dysregulation and pain with and without acute beta-blockade in women with fibromyalgia and temporomandibular disorder. J Pain. 2009:10(5):542-52

62. Solberg Nes L, Carlson CR, Crofford LJ, de Leeuw R, Segerstrom SC Self-regulatory deficits in fibromyalgia and temporomandibular disorders. Pain. 2010:151(1):37-44

63. Maixner W, Greenspan JD, Dubner R, Bair E, Mulkey F, Miller V, et al. Potential autonomic risk factors for chronic TMD: descriptive data and empirically identified domains from the OPPERA case-control study. J Pain. 2011;12(11 Suppl):T75-91.
64. Hallman DM, Lyskov E. Autonomic regulation, physical activity and perceived stress in subjects with musculoskeletal pain: 24-hour ambulatory monitoring. Int J Psychophysiol. 2012;86(3):276-82.

65. Chalaye P, Goffaux P, Bourgault P, Lafrenaye S, Devroede G, Watier A, et al. Comparing pain modulation and autonomic responses in fibromyalgia and irritable bowel syndrome patients. Clin J Pain. 2012;28(6):519-26.

66. Reyes Del Paso GA, Garrido S, Pulgar A, Martin-Vazquez M, Duschek S. Aberrances in autonomic cardiovascular regulation in fibromyalgia syndrome and their relevance for clinical pain reports. Psychosom Med. 2010:72(5):462-70.

67. Figueroa A, Kingsley JD, McMillan V, Panton LB. Resistance exercise training improves heart rate variability in women with fibromyalgia. Clin Physiol Funct Imaging. 2008:28(1):49-54.

68. Kelemen J, Lang E, Balint G, Trocsanyi M, Muller W. Orthostatic sympathetic derangement of baroreflex in patients with fibromyalgia. J Rheumatol. 1998;25(4):823-5.

69. Bruehl S, Chung OY. Interactions between the cardiovascular and pain regulatory systems: an updated review of mechanisms and possible alterations in chronic pain. Neurosci Biobehav Rev. 2004;28(4):395-414

70. Dworkin BR, Elbert T, Rau H, Birbaumer N, Pauli P, Droste C, et al. Central effects of baroreceptor activation in humans: attenuation of skeletal reflexes and pain perception. Proc Nat Acad Sci U S A. 1994:91(14):6329-33.

71. Randich A, Maixner W. Interactions between cardiovascular and pain regulatory systems. Neurosci Biobehav Rev. 1984;8(3):343-67.

72. Reyes del Paso GA, Garrido S, Pulgar A, Duschek S. Autonomic cardiovascular control and responses to experimental pain stimulation in fibromyalgia syndrome. J Psychosom Res. 2011;70(2):125-34.

73. Martinez-Lavin M, Hermosillo AG. Autonomic nervous system dysfunction may explain the multisystem features of fibromyalgia. Semin Arthritis Rheum. 2000;29(4):197-9

74. Mueller A, Strahler J, Armbruster D, Lesch KP, Brocke B, Kirschbaum C. Genetic contributions to acute autonomic stress responsiveness in children. Int J Psychophysiol. 2012;83(3):302-8.

75. Olsson CA, Anney RJ, Lotfi-Miri M, Byrnes GB, Williamson R, Patton GC. Association between the COMT Val158Met polymorphism and propensity to anxiety in an Australian population-based longitudinal study of adolescent health. Psychiatr Genet. 2005:15(2):109-15.

76. Diatchenko L, Nackley AG, Slade GD, Bhalang K, Belfer I, Max MB, et al. Catechol-O-methyltransferase gene polymorphisms are associated with multiple pain-evoking stimuli. Pain. 2006:125(3):216-24

77. Zubieta JK, Heitzeg MM, Smith YR, Bueller JA, Xu K, Xu Y, et al. COMT val158met genotype affects mu-opioid neurotransmitter responses to a pain stressor. Science. 2003:299(5610):1240-3.

78. Smith SB, Maixner DW, Greenspan JD, Dubner R, Fillingim RB, Ohrbach R, et al. Potential genetic risk factors for chronic TMD: genetic associations from the OPPERA case control study. J Pain. 2011:12(11 Suppl):T92-101.

79. Diatchenko L, Anderson AD, Slade GD, Fillingim RB, Shabalina SA, Higgins TJ, et al. Three major haplotypes of the beta2 adrenergic receptor define psychological profile, blood pressure, and the risk for development of a common musculoskeletal pain disorder. Am J Med Genet B Neuropsychiatr Genet. 2006;141B(5):449-6. 